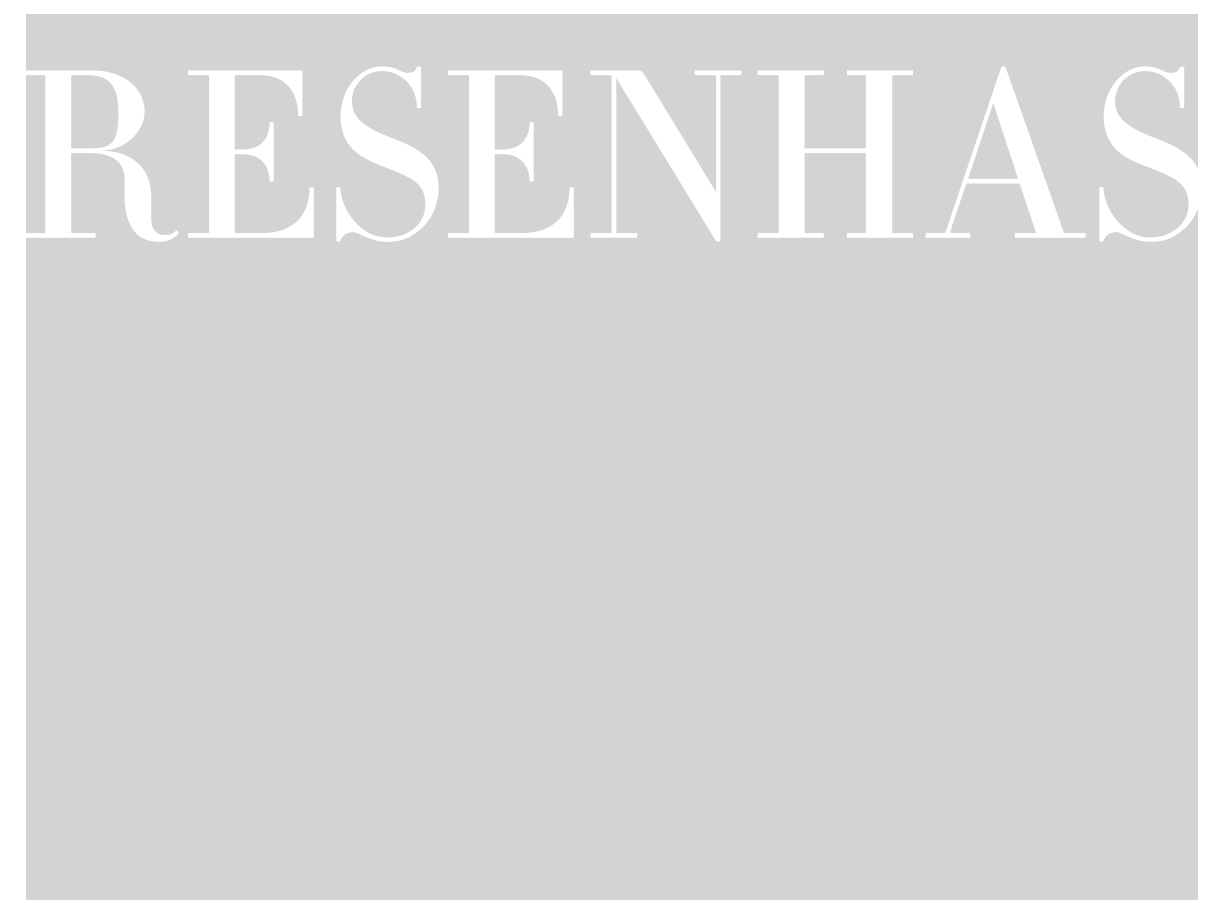

\title{
OS DESAFIOS PARA MATERIALIZAÇÃO DO PLANO NACIONAL DE EDUCAÇÃO NO BRASIL
}

https://doi.org/10.1590/198053145066

\section{LUIZ ALBERTO RIBEIRO RODRIGUES'}

DOURADO, Luiz Fernandes. Plano Nacional de Educação: o epicentro das políticas de estado para a educação brasileira. Goiânia: Editora da Imprensa Universitária; Anpae, 2017. 216 p.

Essa publicação de Luiz Dourado (2017) apresenta um balanço crítico analítico em relação aos três anos de vigência do Plano Nacional de Educação (PNE 2014-2017), no contexto histórico do planejamento educacional brasileiro. Recupera aspectos minuciosos e articulados do processo de construção de políticas educacionais pactuadas na esfera pública, no período de quase duas décadas recentes.

Nesse contexto, o propósito do autor é analisar historicamente a relação entre o planejamento no Brasil e os planos nacionais de educação, com foco no conjunto de políticas recentes, que recuam acordos e impactam diretamente nas condições à materialização do atual PNE.

Desse modo, a ideia do PNE como epicentro das políticas de Estado para a educação brasileira - metáfora embasada nos conceitos da geofísica - se refere ao lugar de destaque que ele ocupa, no ponto mais elevado e central da luta da sociedade por uma política educacional, em contextos de consenso, e de contradição, marcados por disputas de projetos em torno do papel do Estado. 
Assim, a análise posta indica que o PNE é atingido, em primeiro lugar, pelo desmonte educacional decorrente das decisões do governo Temer (2016 até os dias atuais) e, nesse sentido, corre riscos de inviabilidade no cumprimento dos compromissos assumidos, em razão de políticas voltadas ao favorecimento de setores privados e da adoção de políticas de ajuste fiscal.

A partir desses argumentos, no primeiro capítulo, Dourado (2017) apresenta uma valiosa retrospectiva histórica acerca das discussões sobre a proposição e materialização de planos nacionais para a educação. Mesmo que de modo sucinto, o autor resgata o movimento que ocorre no Brasil desde a década de 1930, até o PNE de 2014, marcado por disputas em torno de projetos para uma educação pública, diante de interesses e projetos privados, sobretudo relacionados à questão do financiamento e da gestão da educação.

Nesse quadro analítico, dois distintos olhares orientam a ideia de planejamento da educação no período de 1930 a 2014, sem no entanto configurar ou constituir-se efetivamente como planos nacionais de educação. Como observa o autor, os documentos da educação estiveram ora vinculados a planos de desenvolvimento econômico do País, ora pensados na perspectiva da sistematização de suas etapas, a partir de diferentes concepções filosóficas acerca da educação.

Resgata-se, nesse sentido, as primeiras ideias de Plano Nacional de Educação, originadas no ideário escolanovista, a partir do Manifesto dos Pioneiros da Educação Nova, em 1932, e, a partir daí, a institucionalização do compromisso constitucional da União em fixar o Plano Nacional de Educação. Partindo desse resgate histórico, foi observado que, em 1946, há uma desmobilização em torno desse compromisso, ano em que a Constituição Federal (CF) atribuiu à União competência para legislar sobre Diretrizes e Bases da Educação Nacional. Deixa-se de lado a ideia do PNE, só retomado em 1967, quando a CF volta a estabelecer o compromisso da União para com a elaboração do PNE, surgindo daí um Plano Nacional para o período de 1968-1971.

Assim, na lógica da educação como desenvolvimento, encontra-se o Plano de Educação elaborado no governo de Juscelino Kubitschek (1956-1960), em que a educação foi planejada como uma das estratégias para Plano Global de Desenvolvimento (1968-1971); o Programa de Ação Econômica do Governo (1964-1966), que considerou a educação no sentido das consequências econômicas; e ainda o III Plano Nacional de Desenvolvimento (1980-1985), que foca a educação como um direito social.

Em outra lógica, a concepção de Plano se vincula à organização da educação em etapas (ensino primário, ensino médio e ensino superior), tendo como eixo de referência a história da Lei de Diretrizes e Bases (LDB), a partir de 1961, que veio a ser desmontada com o golpe de 
1964. A partir daí, em 1968, veio a Reforma Universitária e, em 1971, alteraram-se a estrutura e o funcionamento do ensino.

É na CF de 1988 (BRASIL, 1988) que há de fato um avanço considerável no planejamento educacional, ao inserir-se a educação no campo dos direitos sociais. Nessa direção vai o PNE 2001-2010, ao estabelecer uma atenção à educação como um direito, à luz de princípios, de sua obrigatoriedade, das condições de oferta, da gestão e do seu financiamento em todos os níveis.

Um marco desse novo tempo é o papel que assume o Fundo de Desenvolvimento da Educação Básica (Fundeb), ao romper a lógica das políticas centradas no ensino fundamental, assumindo, a partir de então, os recursos e as condições políticas ao desenvolvimento da educação básica e de valorização dos profissionais de educação.

Desse modo, nessa mesma década, outra referência às políticas educacionais é dada ao Plano de Desenvolvimento da Educação (PDE), criado em 2007 pelo governo federal. Originado no PDE escola, o PDE educação universalizou uma estratégia de financiamento de programas diretamente à escola, através do Programa Dinheiro Direto na Escola (PDDE).

Dourado (2017) atribui ainda uma importante referência política ao papel da participação da sociedade no planejamento educacional, realizado por meio das conferências nacionais de educação, com destaque à Conferência de Educação Básica (Coneb), em 2008, e às conferências nacionais de educação (Conae), de 2010 e 2014, bem como a todas as conferências estaduais e municipais que as antecederam. Dessa forma, segundo o autor, o esforço histórico em torno da garantia do direito à educação, pela construção de um sistema nacional de educação, traduzida na construção coletiva das políticas de Estado, desafia o "Estado brasileiro a garantir a materialização do PNE” e revela sistematicamente o movimento da sociedade civil e política no acompanhamento do PNE (DOURADO, 2017, p. 40).

No quadro dessas ideias, o capítulo 2 analisa, a partir de notas teóricas, os avanços, limites e ambiguidades do PNE, com base na tese de que ele se constitui como eixo das políticas educativas. Dourado (2017) utiliza-se de referenciais teóricos gramscianos para situar as contradições inerentes ao conceito de Estado como "expressão da correlação de forças contraditórias", não se limitando à classe dominante. Assim, considera o Estado "ampliado (integral) que não se reduz ao governo [...] espaço e força efetiva para a consciência e organização das classes sociais" (DOURADO, 2017, p. 77).

$\mathrm{O}$ autor utiliza-se ainda das ideias de $\mathrm{S}$. Ball a respeito da teoria do ciclo de política, para explicar o caráter não linear, mas de movimento, em que ocorrem as políticas após sua produção. Diferencia-se, assim, o processo de proposição das políticas de sua efetiva prática. 
Sustenta, desse modo, que o movimento das políticas não ocorre na direção de sua implementação, mas do seu desenvolvimento, da interpretação criativa.

Assim sendo, os conceitos de Estado "ampliado" e de política pública como ciclo em desenvolvimento são fundamentais para a avaliação do PNE em suas diferentes fases, desde o processo de sua produção, aprovação até o desafiador período de materialização, conforme proposto por Dourado, nesta obra, "como política pública, na qualidade de expressão da articulação entre epistemologia, e política, subjetividade e objetividade, cotidiano e estrutural social" (2017, p. 41). Ganha sentido, nessa lógica avaliativa, a atuação de entidades e de órgãos educacionais na "tramitação do Plano, apresentação de emendas, mobilizações, manifestações, elaboração de documento e notas públicas", em um ambiente de disputas de concepções acerca "da relação sociedade e educação, público e privado, qualidade, gestão, avaliação e regulação, diversidade e educação" (p. 47).

É nesse ambiente de disputa e embates por concepções fundamentais da política educacional que Dourado analisa, no $3^{\circ}$ capítulo, o processo de materialização do PNE. A avaliação das metas do PNE, postas nesse capítulo, considera a articulação entre aspectos da quantidade e qualidade, referenciados em Gramsci, como categorias centrais inerentes a todos os fenômenos. Deve-se observar que, conforme Gramsci, os termos quantidade e qualidade são, de certo modo, inseparáveis. Refere-se o primeiro ao que se quer desenvolver, ao "aspecto corpóreo do real", e qualidade é posta como problema "pelo único modo no qual tal desenvolvimento é controlável e mensurável” (DOURADO, 2017, p. 77). O capítulo visa, assim, a realizar uma análise por meta, na direção da “compreensão dos limites e possibilidades do PNE (2014-2018) e para os desafios à sua efetiva materialização” (p.73).

Nesse contexto, um ingrediente central nesse processo de disputa, especialmente quanto ao financiamento, são as articulações políticas de setores privados, pondo riscos à política por formatos de privatização, alterando a concepção de que financiamento público é exclusivo para o setor público, contrariando os princípios de cooperação e colaboração, marcos da relação que propõe o PNE entre os entes federados.

Merece destaque ainda a questão do ensino médio, objeto da Meta 3, ao propor medidas de superação, entre elas o Mais Educação, o Programa Ensino Médio Inovador e as discussões relacionadas à Reforma do Ensino Médio e que foram atropeladas pela MP 746, encaminhada pelo governo Temer. A Reforma do Ensino Médio, como chamou o governo, apresentou-se frágil e controvertida, sofrendo inúmeras críticas da sociedade civil, dos especialistas e até de parlamentares. Nessa reforma são apontadas fragilidades e contradições na redução da complexidade do currículo em apenas algumas ênfases ou itinerários 
formativos, o que implicará a negação do direito às múltiplas oportunidades formativas e à formação básica comum, além de provocar um estrago significativo na atual LDB. Essa reforma ainda aguarda a Base Nacional Comum Curricular (BNCC) para essa etapa, a fim de definir estratégias para operacionalização.

Situa ainda esta obra questões de concepção em torno da BNCC. A primeira posição em defesa do papel da União na coordenação das políticas nacionais, incluído aí a BNCC; a segunda entende a BNCC como a definição de um currículo mínimo nacional; e a outra visão, em defesa do currículo local. Uma questão central em torno da BNCC é sua vinculação às avaliações externas e ao controle do trabalho docente.

Compreende-se, pois, que os desafios à materialização do PNE são, de fato, complexos, "especialmente, se a luta política for pela sua materialização como Plano de Estado que visa a democratização do acesso, permanência e gestão com qualidade à educação básica e superior" (p. 177). Porém, a médio e longo prazo, o impacto maior à materialização do PNE vincula-se ao corte nos investimentos em educação impostos pela chamada $\mathrm{PEC}^{1}$ dos gastos.

Assim, como articulador do Sistema Nacional de Educação, a vitalidade do PNE carece da "necessária articulação entre planos nacional e subnacionais aos outros instrumentos de planejamento, como o Plano de Ações Articuladas e os planos plurianuais" (p. 178) e requer organização e mobilização da sociedade civil em defesa do PNE, marco histórico dos esforços e avanços na última década.

Com essa obra, Luiz Dourado (2017) coloca à disposição da comunidade acadêmica uma fonte inicial de pesquisa que traduz em linguagem simples a complexidade da política educacional no Brasil, em diferentes fases de produção e materialização. Constitui um sólido registro de quem viveu intensamente os principais fatos recentes da política educacional no Brasil, ora como pesquisador, ora como membro do Conselho Nacional de Educação e ora como militante da política educacional.

\section{REFERÊNCIAS}

BRASIL. Constituição da República Federativa do Brasil (1988). Brasília, DF: Senado Federal, 1988.

DOURADO, Luiz Fernandes. Plano Nacional de Educação: o epicentro das políticas de estado para a educação brasileira. Goiânia: Editora da Imprensa Universitária; Anpae, 2017. 216 p. ISBN: 978-85-93380-18-1

Recebido em: 29 OUTUBRO 2017 | Aprovado para publicação em: 27 MARÇO 2018

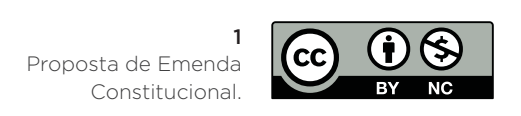

Este é um texto de acesso aberto distribuído nos termos da licença Creative Commons do tipo BY-NC. 